\title{
EL FENÓMENO DEL TRUEQUE: UNA MIRADA SOCIOLÓGICA
}

\author{
Claudia Gatti \\ claudia.gatti@hotmail.it \\ UNIVERSIDAD DE LOS ESTUDIOS DE ROMA TRE
}

\begin{abstract}
RESUMEN
Entre las varias respuestas sociales a la crisis argentina, el fenómeno del trueque ${ }^{1}$ es una de las más interesantes. Presenta muchas de las características e instancias de los demás fenómenos pero en una síntesis original: nace al interior de la clase media en decadencia, con el objetivo de hacer frente a la falta de trabajo y dinero, a través de un acción colectiva autogestionada e independiente de cualquier institución; crece de manera exponencial, involucrando a todas las clases sociales y asegurando la supervivencia - durante los ocho meses más críticos - a sietes millones de personas; es un fenómeno que defiende el derecho al trabajo y a la supervivencia en modo pacífico y propositivo, sin reclamar la intervención estatal sino estructurando un sistema económico complementario al capitalista; promueve y fortalece la «cultura del trabajo», prácticamente inexistente entre los pertenecientes a la pobreza estructural acostumbrados a vivir del asistencialismo peronista, y contribuye a reconstruir los lazos de solidaridad entre las personas desarticuladas por el individualismo capitalista.
\end{abstract}

Palabras clave: Economía informal, economía social, monedas sociales, movimientos de autoorganización argentinos. 


\begin{abstract}
The Trueque phenomenon is one of the most interesting responses between the different social answers to the Argentinean crisis, because it presents many characteristics and instances typical of the other phenomena in an original synthesis. It arises in the declines middle class with the purpose of confronting the jobs and money deficiency through a selforganized collective action independent of any institution. It grows in an exponential way involving all social classes and ensuring the survival (during the most critical eight months) of seven million people. It is a phenomenon that defends the right to work and the survival in a pacific and resourceful way, without asking for the state intervention but structuring an economical system complementary to the capitalism system. It promotes and fortifies the «work culture», practically non-existent between belongings to the structural poverty that are in the habit of living of the «peronist asistencialismo»; it contributes $t$ reconstruct confidence ties between people isolated by capitalist individualism.
\end{abstract}

Key words: Informal economy, social economy, social money, Argentinean movements of self organization. 


\section{INTRODUCCIÓN}

La crisis argentina se presenta como un hecho de crónica tanto política, mediática, judicial como económica. Sin embargo, los más atentos logran superar la crónica para enmarcar el hecho en la historia: estos hechos, que terminaron en el default económico y en las rebeliones de plaza en diciembre de 2001, son intentos de cerrar la crisis, una crisis que empezó por lo menos hace treinta años.

Al analizar el contexto histórico, la crisis política tiene de hecho su historia, una historia que, por ponerle un inicio, empieza con la dictadura militar en 1976, impuesta por la oligarquía latifundista e industrial para implementar su propia política neoliberal, apoyada activamente por el gobierno estadounidense (Di Tella 1998, Seoane 2003). La «guerrilla», que veía contrapuestos los diferentes grupos de izquierda a los de derecha ya desde 1974, durante la dictadura se trasformó en una guerra sucia y silenciosa en la que fueron físicamente aniquilados todos los grupos políticos que se oponían al régimen dictatorial - los tristemente famosos treinta mil desaparecidos-, dejando una herida todavía abierta dentro de la sociedad argentina. Esta herida se vio profundizada por las democracias que se sucedieron — de 1983 hasta hoy — ya que no lograron independizarse de los poderes que sostenían la dictadura. Los responsables materiales e ideológicos — salvo contados casos - todavía no han sido condenados por la justicia, y la sociedad aún no ha tomado conciencia de las consecuencias provocadas.

De igual manera la crisis económica tiene su historia, vinculada con la historia de la oligarquía latifundista e industrial que, desde 1976, sostenida e incentivada sistemáticamente por las políticas neoliberales del Banco Mundial y del Fondo Monetario Internacional, traslada sus intereses e «inversiones» a la economía financiera, cambiando paulatinamente la estructura económica-productiva del país. En el proceso de financiarización de la economía ${ }^{2}$ argentina se vislumbra más que una racionalidad económica la constante persecución de los intereses económicos y políticos de una clase dirigente que durante treinta años ha «saqueado» ${ }^{3}$ al propio país sus recursos económicos, naturales y sociales para obtener un beneficio personal.

Ahora bien, analizar la crisis social dentro de un contexto histórico propio se nos vuelve más complejo. Si bien, en parte, coincide con los marcos políticos y económicos, la 
historia de la crisis social es más complicada, más episódica, con diversos actores involucrados. Se manifestó al mundo entero a través de las imágenes de una Plaza de Mayo invadida por una multitud enojada que gritaba a la clase política: «QQue se vayan todos!». Imágenes que mostraron la grave fractura social que ha ido profundizándose durante estos últimos treinta años de políticas económicas neoliberales que polarizan la sociedad: una pequeña parte se enriquece a espaldas de la mayoría, que ve empeorar progresivamente su calidad de vida o hasta se le niega el derecho a la supervivencia.

Asimismo en la historia de la crisis social argentina se pueden detectar muchas otras «historias» que se anclan en el contestatario espíritu argentino y tiene como objetivo «preservar», «defender» aquellos derechos ya adquiridos — salarios dignos, determinadas condiciones de trabajo, salud y educación pública-, poniendo en acto, a su vez, experiencias de autogestión que de hecho proponen una sociedad diferente con modos de producción y reproducción social autónomos y autogestionados. Son fenómenos que crean espacios de supervivencia, espacios autogobernados a través de una gestión horizontal; espacios de resistencia. ${ }^{4}$

Los obreros que deciden tomar y poner en producción las fábricas cerradas por los dueños para defender su fuente de trabajo y su dignidad, mostrando que la gestión obrera de una empresa es posible, crean espacios de resistencia. Las «fábricas recuperadas» han entrado en el imaginario colectivo de los argentinos no solamente porque defienden el derecho al trabajo, sino también por sus éxitos productivos. Del mismo modo, crean espacios de resistencia y de supervivencia los «piqueteros», los movimientos de trabajadores desocupados que empezaron a cortar las grandes vías de comunicación, vitales para el capitalismo contemporáneo, y continuar su lucha por la reivindicación de una vida digna a través de la construcción de comunidades autogestionadas en espacios ocupados y resignificados. También las «asambleas barriales» resignifican y dan nueva vida a plazas y calles, pues cuestionan el principio de representación y empiezan a autogestionar la vida dentro de los barrios a través de acciones comunitarias que producen servicios sociales de base para los habitantes del barrio y de los sectores más golpeados.

Nacen así fenómenos sociales que no reclaman sus derechos a las instituciones estatales, sino simplemente dan vida, a través de la acción colectiva, a aquello que 
necesitan: los «cartoneros» se inventan un trabajo, recolectando y vendiendo papel, vidrio, plástico, creando así el único sistema de clasificación de residuos de Buenos Aires que fue luego institucionalizado; otros grupos organizan huertas comunitarias, hornos comunitarios, roperos comunitarios, que les permiten satisfacer sus necesidades básicas. ${ }^{5}$

En este marco el trueque es uno de los tantos «fenómenos» de la crisis social argentina. El trueque se encuentra a mitad de camino entre los movimientos colectivos de protesta y los movimientos positivamente reformistas: es al mismo tiempo protesta y propuesta, utopia y concreción, está a favor y en contra de las instituciones.

\section{HISTORIA DEL FENÓMENO}

El fenómeno del trueque nace con el primer Club de Trueque el 1 de mayo de 1995 en Bernal, barrio del área metropolitana de Buenos Aires, en el seno del Programa de Autosuficiencia Regional desarrollado por un grupo de ecologistas de clase media. ${ }^{6}$ Tal programa se proponía aplicar las ideas ecologistas a la economía con el fin de promover el desarrollo local sustentable a través de la «producción» de alimentos en huertas tecnológicas, el «ahorro» energético y tecnológico obtenido gracias a la casa ecológica, la «distribución»y el «intercambio» de los productos en el Club de Trueque.

El Club de Trueque es prácticamente un mercado en el cual los productos son intercambiados por medio del trueque. Los fundadores ${ }^{7}$ especifican que no se trata del antiguo ${ }^{8}$ trueque sino de un «trueque multirecíproco», o sea, de una modalidad de intercambio no monetaria que involucra a varias personas y a varios productos en el mismo mercado. En la base de este nuevo sistema socioeconómico debía haber una nueva sociabilidad y relaciones de intercambio no mediadas por el dinero. El Club de Trueque debería haber sido un lugar de intercambio reservado a sujetos marginados por el sistema económico formal, desocupados o subocupados, que sin embargo podían ofrecer un servicio o un producto. De hecho, desde los años 90 la crisis económica había comenzado a afectar también a la clase media, causando el aumento de la tasa de desempleo y una fuerte disminución de la masa monetaria en circulación. ${ }^{9}$ Nace así la exigencia de valorar de otro modo las capacidades laborales de las personas excluidas del mercado formal a través de formas de producción y de intercambio autónomas e independientes de las instituciones. En 
el Club de Trueque era posible encontrar trabajo y no empleo, era posible prescindir del dinero porque los productos, los servicios y los saberes, podían ser intercambiados directamente o a través de un medio simbólico de intercambio que iría cambiando de forma a lo largo de la experiencia. Las personas que decidían entrar en este «mercado paralelo» debían producir y consumir en igual medida, tornándose así «prosumidores».

De este modo, la idea del Club de Trueque nace al interior de la clase media argentina - que hace veinte años era considerada la más rica y estable de América Latinacon el objetivo de mejorar la propia calidad de vida. Para participar en el Club de Trueque era necesario contar con una pequeña suma de dinero e invertirla y valorarla con el propio trabajo. En este mercado semanal los prosumidores intercambiaban hortalizas, frutas, huevos, alimentos elaborados, productos artesanales con cuero, madera, etc. Al principio los intercambios eran registrados en una base de datos; después, con el aumento de los participantes y la apertura de nuevos clubes, comenzaron a utilizarse unos vales, unos bonos llamados créditos. Al inicio eran personales y cada uno los emitía en relación con el valor de lo que producía; después, el mismo Club comenzó a emitir los créditos y a prestar a cada usuario una suma de créditos que debían ser devueltos al salir del Club.

El fenómeno se expandió en poco tiempo a toda el área metropolitana de Buenos Aires y después a toda Argentina, hasta que en 1997 los Clubes de Trueque en el país ya eran setenta; entonces comenzaron a ser llamados nodos, ya que participaban en una misma red: Red Global del Trueque, RGT. En el mismo año los nodos de la red se agrupaban en subzonas, y para generar practicidad unificaron el crédito. El gobierno de la ciudad en el mismo año implementó iniciativas para promover el trueque. En 1998 las diferentes zonas se encontraron mensualmente en una reunión llamada Interzonal para discutir temas inherentes a la organización, emisión y control de los créditos.

Ciertas zonas empezaron a alejarse de RGT hasta que, para preservar una posición de prestigio en la organización, en mayo de 1999 los fundadores editaron una publicación llamada Franchising Social, que vendían a dos pesos. Con esta publicación pretendían defender y promover el originario modelo de Club de Trueque, e incluyeron cincuenta créditos en la revista - misma suma que antes prestaban a cada nuevo prosumidor-. RGT justificó este hecho - aquello que otros definieron como «venta de créditos»— como una 
manera de financiar la asociación que ya contaba con 120,000 socios. La ruptura entre las diferentes zonas indujo a los fundadores a salir de la Interzonal en octubre de 2000; en enero de 2001 Sampayo salió de la Interzonal y fundó una nueva red: el Club de Trueque Zona Oeste; en abril de 2001 Heloisa Primavera y Charly fundaron la Red del Trueque Solidario, a la cual adhirieron las zonas que habían quedado en la Interzonal. Estas divisiones fueron causadas por divergencias ideológicas y por una intensa lucha por el comando y la gestión de los créditos, ya definidos como los «nuevos dólares». En enero de 2001 los nodos eran 500 en todo el país e involucraban a 320,000 personas, pero a partir de octubre de 2001 los usuarios crecieron de manera exponencial por la cancelación de los planes de desempleo que fueron reactivados en mayo 2002. Durante estos ocho meses, siete millones de argentinos sobrevivieron gracias al Club de Trueque, que se tornó una estrategia de supervivencia para el sector más pobre de la sociedad argentina.

Por el contrario, la clase media comenzó a alejarse de un sistema que ya no tenía los principios de solidaridad del inicio, de equidad entre producción y consumo, por causa de la ola de personas que, aun no teniendo capacidad productiva, entraron en el sistema para consumir «lo que podían». En mayo de 2002 dejó RTG de aceptar inscripciones y perdió totalmente el control de los nodos y de los créditos; a este cuadro se le unió un grave fenómeno de falsificación de créditos que contribuyó a la pérdida de confianza en el sistema. En el mismo mayo de 2002 existían 6,000 Clubes de Trueque, pero al final de 2002 quedaban solamente 1.000. En 2003 RGT implementó un programa de reactivación de un sistema que «se les había escapado de las manos» a sus mismos ideadores, no porque la gente se hubiera apropiado del sistema sino porque la capacidad de producción y distribución de éste fue utilizada de manera incoherente con respecto a las modalidades de funcionamiento del mismo, causando así su colapso.

El «experimento social» del trueque siguió siendo desarrollado por los fundadores con una conciencia madura sobre la complejidad de la gestión de «otro» sistema, y por los usuarios dada la capacidad del sistema para hacer frente a las distintas necesidades sociales. La historia o, mejor dicho, «las historias» del trueque son complejas, pero ninguna de ellas negaría que el trueque es uno de los fenómenos sociales que en Argentina demostró cómo la riqueza de la sociedad civil puede hacer frente a la pobreza de las instituciones. 


\section{EL PROYECTO Y LAS PRÁCTICAS}

Ya desde sus inicios el fenómeno del trueque llamó la atención de intelectuales, economistas, sociólogos y antropólogos de universidades, organizaciones internacionales, del poder político, del poder económico, etc. Sin embargo, gran parte del análisis llevado a cabo ha privilegiado un abordaje propiamente económico del fenómeno: se buscaba así una respuesta a interrogantes tales como: ¿es el trueque un modelo alternativo al capitalismo?, ¿es posible una economía no monetaria?, ¿puede ésta coexistir con el capitalismo?, ¿cuáles son las reglas de sustentabilidad y gobernabilidad económica del trueque?, ¿estamos en presencia de una «economía solidaria» y de una «moneda social»? Si bien estos interrogantes son pertinentes, se vuelven absolutamente reduccionistas si no los ubicamos en un análisis más amplio. Del mismo modo, tampoco es apropiado analizar un fenómeno en continua evolución como si fuera una actuación coherente de un proyecto bien estructurado.

A partir de un enfoque socioantropológico nos proponemos destacar los diferentes valores que asumen el proyecto y las prácticas del trueque. Por proyecto entendemos el diseño del sistema económico así como fue pensado y repensado por sus fundadores y por los ideólogos que fueron agregándose durante el desarrollo del proyecto en cuestión.

Los fundadores admiten que nunca existió un proyecto definitivo de Club de Trueque: lo único cierto es que debía ser un instrumento que permitiera una nueva sociabilidad y unas relaciones de intercambio no mediadas por el dinero; la forma y el funcionamiento de los Clubes de Trueque resultaron un experimento continuo que tuvo que ajustarse tanto a las diferentes disputas ideológicas al interior de RGT como a los cambios socioeconómicos devenidos luego de la crisis de 2001.

Los fundadores del trueque se propusieron, sobre todo, la constitución de un sistema de intercambio no monetario más que una «nueva sociabilidad» que se habría generado como consecuencia de estas «nuevas» relaciones de intercambio no monetario. Para ser así considerado, el medio de intercambio no debía presentar la característica de «reserva de valor» propia del dinero por ser ésta la causa del «peor mal del capitalismo»: la acumulación. 
Si bien consideraban al capitalismo un sistema económico contradictorio y no equitativo, el objetivo del trueque no era crear un sistema alternativo al capitalismo sino un sistema paralelo al mercado formal. Su función contemplaba involucrar a los marginados para que desarrollaran experiencias laborales y crearan así su propia actividad con el fin de entrar luego, de manera menos traumática, en el mercado formal.

Es claro, entonces, que el Trueque fue ideado como un «sistema de pasaje» hacia el mercado formal. La lectura del fenómeno como un sistema alternativo al capitalismo surge ya sea al interior del grupo de ideólogos - como Heloisa Primavera y Charly, que intentarán encaminar en tal dirección el fenómeno con la Red del Trueque Solidario, RTS-, como en las universidades, en particular en la Universidad Nacional General Sarmiento, que criticará duramente a RGT acusándola de incoherencia y apoyará la línea de RTS.

Presentado así el proyecto inicial del trueque es útil detenerse sobre el significado real que ha tenido el fenómeno para quienes en él participaron. Los actores sociales que lo hicieron pueden dividirse en dos categorías: ideólogos y usuarios. Desde 1995 hasta 1999 se da un fuerte involucramiento ideológico por parte de los usuarios de los nodos con respecto a los doce principios de RTG. Sin embargo, a partir de 2000, y en coincidencia con la explosión del fenómeno, tal involucramiento comienza a disminuir progresivamente. Esto se verá reflejado en la distancia y la incoherencia cada vez mayor entre las prácticas de los usuarios y el proyecto de los ideólogos. A tal incoherencia es, en parte, imputable la parcial «derrota» del trueque como sistema económico original y distinto.

Las formas culturales de la clase social de pertenencia de los usuarios seguramente han influido en el grado de involucramiento ideológico con respecto al proyecto del trueque, el cual ha sido presentado como un sistema económico que se basaba en una nueva ética: la «ética del ser», contrapuesta a la «ética del tener». Hasta 1999 los usuarios del trueque pertenecían, en su mayoría, a la clase media en decadencia, y encontraban en el nodo un lugar en el cual mejorar su calidad de vida, ya fuera desde el punto de vista económico como social; posteriormente entraron en el sistema usuarios pertenecientes a la capas más pobres de la sociedad, esto determinó una caída de la calidad y la cantidad de los productos intercambiados hasta llegar a la insostenible situación en que cerca de cien mil usuarios 
producían para un millón que solamente consumía. De este modo, el trueque se había trasformado en una estrategia de supervivencia por la cual todos los principios de solidaridad y reciprocidad perdieron importancia frente a la «necesidad de comer». A los usuarios les eran ajenas las disputas teóricas y la mayoría de ellos participaba sin plantearse problemas ni contradicciones en las diferentes redes existentes. Tampoco el proyecto de «reactivación», promovido desde 2003, parece haber conseguido incluir a los usuarios en el proyecto más general del trueque.

Los mismos ideólogos, inducidos por presiones externas y no totalmente concientes de la complejidad del sistema que habían creado, tomaron iniciativas que minaron la sustentabilidad económica del sistema del trueque: en particular, minaron el principio de «prosumisión» - equilibrio entre producción y consumo-, aceptando en el mercado del trueque «objetos» que no habían sido directamente producidos por el usuario que los intercambiaba, como por ejemplo objetos usados o productos provenientes del mercado formal. Esto significó que, en un sistema pensado para la satisfacción de las necesidades básicas, comenzaron a ser introducidas «mercaderías» provenientes de un sistema externo. Tal sistema no producía para satisfacer las necesidades de una comunidad ${ }^{10}$ sino para la venta generalizada; a su vez, producía respecto del valor de cambio del objeto en cuestión y no con respecto a su valor de uso. El desequilibrio entre los dos tipos de producción era inevitable pues se intentaba hacer confluir en un mismo mercado «cosas» producidas por un sistema casi precapitalista - en el cual la tierra y el trabajo no son mercaderías y el valor de las cosas es dado por el tiempo de trabajo empleado en producirlas-, con «cosas» producidas por un sistema capitalista — en el cual el valor es regulado por la ley de la oferta y la demanda-. Se exigía así hacer equivaler la producción y el consumo de un grupo inevitablemente heterogéneo en relación con las expectativas y necesidades.

Conjuntamente a la aceptación de las mercaderías, en los Clubes de Trueque se aceptó también el valor de cambio, intrínseco a la naturaleza misma de la mercadería, y esto a su vez no pudo más que generar el «dinero». De hecho, para facilitar los intercambios, los fundadores introdujeron algo similar al dinero pero que se diferenciaba de éste por estar privado, según su opinión, de la particular propiedad de ser reserva de valor: introdujeron así el «crédito», técnicamente un bono de descuento por el porcentaje total del 
«producto», que debería haber facilitado el intercambio entre productos de valores diferentes, desarrollando las funciones de unidad de medida y de medio de circulación.

El temor de que estos bonos se parecieran demasiado al dinero y que la gente los utilizara como si fueran tal incitó a los fundadores a buscar estrategias para diferenciar de alguna manera el «billete» del crédito de un billete cualquiera: en un primer momento los bonos debían estar firmados por quienes los habían utilizado para ser luego sustituidos por nuevos «billetes»: de esta manera el crédito no parecía una herramienta impersonal y anónima como lo era el dinero. El valor del crédito encierra el valor de producción que se agota en un único intercambio. Sin embargo, la tarea de firmar cada crédito e introducir nuevos créditos ligados a los nuevos intercambios tornó el sistema tan complejo que fue luego abandonado. De todos modos, los créditos siguieron llamándose «bonos de descuento», pero en el reverso, según los diferentes Clubes de Trueque, se incluyeron explicaciones sobre el uso y función de los créditos: la no intercambiabilidad con el dinero de curso legal y la función de facilitar los intercambios. Debido a que estas explicaciones no implicaron un cambio automático en las prácticas de los usuarios, los fundadores encontraron otra estrategia para desalentar la acumulación de los créditos: la oxidación. Cada crédito mantenía su valor durante un año; luego perdía progresivamente su valor a razón de $12 \%$ anual.

A pesar de todas estas precauciones, desde 1999 en adelante los usuarios consideraron y utilizaron los créditos como si fueran dinero: los ahorraban, los acumulaban, tenían siempre como referencia los precios del mercado formal para decidir el valor de sus productos: recrearon así en los nodos las dinámicas propias de la economía capitalista. En consecuencia los Clubes de Trueque sufrieron el problema de la falsificación, la inflación, la creación de pequeños y grandes monopolios y el inesperado fenómeno de los «pobres que explotan a paupérrimos». Fue por esta razón que, una vez perdida la confianza en los créditos por causa de falsificaciones e hiperemisiones, el sistema se colapsó como cualquier sistema monetario. 


\section{«FRACASO» ECONÓMICO Y ÉXITO SOCIAL}

Si bien en parte se reproducían las dinámicas del sistema capitalista, la gente continuó participando en el trueque ya que, de todas las maneras, obtenían un beneficio económico. El trueque era un sistema abierto a todos, un sistema que no exigía garantías, un sistema que aceptaba e incluía a los marginados del mercado formal. Es innegable que este sistema, nacido por exigencias prácticas, sobre todo económicas de los mismos protagonistas y de su clase pertenencia — esa clase media argentina que veía empeorar de manera incesante la calidad de vida a la cual estaba acostumbrada y que se tornaba cada vez más pobre-, haya obtenido el objetivo que se había fijado: mejorar la vida de las personas, solucionando el problema de la insuficiencia de dinero y el desempleo.

Sin embargo, no consiguió alcanzar el objetivo de ser un sistema no monetario. La utopía de un mercado sin dinero que pudiera convivir con el mercado capitalista fracasó ante la potencia y la invasión de las mercaderías, del valor de cambio, del dinero, de los valores y las prácticas que impregnaron todas las relaciones sociales. El proyecto de cambiar las relaciones de producción capitalista $-\mathrm{y}$ las relaciones sociales en éste basadas - variando sólo la forma del dinero y refugiándose en un pasado premonetario no podía más que naufragar. El creer que el problema del capitalismo está solamente en el dinero en cuanto reserva de valor y que, eliminando tal característica, se logra eliminar las contradicciones del capitalismo, es fruto de un análisis muy superficial. ${ }^{11}$ De hecho, la falta de dinero de curso legal no fue resuelta con una vuelta al trueque, sino con la sustitución de este dinero con un dinero de tipo «privado». Los ideólogos definen los créditos como «moneda social», pero el hecho mismo de no haber sido verdaderamente una «moneda social»—o sea creada, administrada y controlada por toda la comunidad— provocó, con el paso del tiempo, una pérdida de confianza en los créditos.

Tal vez por causa de la evolución demasiado rápida del fenómeno fue evidente la falta de un proceso de autogestión colectiva, no solo de la moneda sino del fenómeno en general. En las distintas redes fueron reproducidas las relaciones jerárquicas que cristalizaron una división entre ideólogos/dirigentes y prosumidores, de manera que las dos categorías practicaron y vivieron el trueque con finalidades y modalidades distintas. 
Resultó así un sistema lleno de contradicciones, sobre todo al obstinarse en considerarlo un «sistema económico alternativo» al capitalismo, objetivo que los fundadores nunca se propusieron pero que ciertos intelectuales continúan proponiendo como única clave de análisis y como criterio último para juzgar sus éxitos.

Al considerar los éxitos de la experiencia del trueque como sistema económico es posible afirmar que nunca existió en tanto sistema alternativo al sistema capitalista, sino que lo hizo efectivamente en tanto sistema complementario a éste, permitiendo la reproducción material y social de siete millones de personas: es posible también sostener que el trueque ha fracasado en tanto sistema económico no monetario y que ha presentado las características de un sistema económico solidario sólo hasta 1999. Con respecto a los «principios» elaborados por los fundadores, el trueque fracasó porque no fue capaz de eliminar las dinámicas y las prácticas capitalistas, o sea, las «mercaderías» y el «dinero».

No obstante, es posible afirmar que el verdadero éxito del trueque se encuentra en sus efectos imprevistos y las funciones latentes ${ }^{12}$ que tienen, que se relacionan con la dimensión económica, social y política del fenómeno. Las funciones latentes analizadas subrayan que el trueque satisface varias necesidades sociales que van más allá de la simple necesidad del sustento material, aunque los prosumidores adjudican una motivación sobre todo económica a la propia participación.

A partir del análisis de las funciones latentes resulta evidente que muchas personas comenzaron a participar en el trueque para salir del aislamiento y de la depresión causada por la pérdida del empleo y, como consecuencia, de un conjunto de relaciones sociales.

[Con el Club de Trueque] uno no se deprime, se distrae, conoce gente, intercambia conocimientos y culturas. $^{13}$

Antes [de participar en el Club de Trueque] tenía la moral baja, estaba deprimida, ahora ya no. ${ }^{14}$

[El Trueque ha cambiado mi vida] económica y humanamente: te relacionás con gente [de] diferentes clases sociales, de diferentes edades; tenés la ocasión de conocer los problemas de los otros, de desahogarte, es un poco como ir al psicólogo. ${ }^{15}$ 
El Trueque cambió $80 \%$ de mi vida, sobre todo por lo que está relacionado al contacto con la gente y el trabajo. ${ }^{16}$

El Club de Trueque deviene un lugar en el cual se socializan los problemas causados por el desempleo y en el cual se buscan soluciones de forma colectiva. Aquello que las personas logran encontrar en el trueque no es la posibilidad de un empleo sino de un «trabajo», o sea de una actividad social que los hacen sentirse útiles, necesarios para la vida de una comunidad: y a través del trabajo, con y por los demás, a través del intercambio y la interacción constante con los demás participantes, las personas logran salir de esa depresión causada por la marginación laboral y social. De ahí que muchos reconocen en el trueque un efecto de terapia de grupo.

[Para mí, el trueque] es como una terapia, es como estar con amigos. ${ }^{17}$

[El trueque] me saca el estrés, no es solamente un negocio, es una excusa para estar con la gente, una terapia. $^{18}$

La participación en el Club de Trueque permite recrear los lazos sociales que los sujetos instauran cuando tienen la posibilidad de actuar en la sociedad, es decir, de trabajar. Las personas se sienten mejor y se sienten mejores porque sus trabajos vuelven a tener valor para una comunidad, la del trueque.

Me siento útil. ${ }^{19}$

Me siento mejor y además estoy en medio de la gente con tranquilidad. ${ }^{20}$

[En el Club de Trueque] lo que sabés hacer vale, y esto te anima y te ayuda también económicamente. $^{21}$

[Aquí] ahora hago un trabajo que me gusta y puedo pagarme también las clases de bordado. ${ }^{22}$

Los «jefes de familia», en modo particular, readquieren la dignidad y la confianza en sí mismos y en sus capacidades productivas cuando perciben que, participando en el trueque, 
pueden continuar solventando las necesidades de sus familias. En el trueque todos redescubren sus capacidades de trasformar la realidad, de producir cosas o servicios, todos pueden y deben contribuir al mantenimiento de la comunidad a través de su trabajo.

[Participar en el Club de Trueque] es un esparcimiento, es hacer algo para sentirse útiles entre la gente. $^{23}$

[Participar en el Club de Trueque] hace sentir [a] la gente útil. ${ }^{24}$

Al comienzo muchos hombres consideraban humillante participar en el trueque para sobrevivir y, de hecho, la mayoría de las veces fueron las mujeres quienes condujeron a sus maridos al Club de Trueque. Las mujeres adquirieron una posición relevante en este fenómeno: son las primeras en dejar de lado cualquier orgullo y en «remangarse»; son las que más fácilmente encontraron algo para producir: alimentos elaborados, indumentarias hechas a mano, tejidas. Culturalmente las mujeres están acostumbradas al trabajo «informal», dado que su trabajo fundamental es el cuidado de la casa y de la familia y nunca es pagado. Son las mujeres quienes, gracias a los muchos recursos que provienen de la conducción de la empresa más difícil de administrar, la familia, logran llevar a casa lo necesario para el sustento familiar. A través de la participación en el trueque, la mujer adquiere un papel preponderante en la familia, sustituye al hombre en la carga de jefe de familia y comienza a sentirse más autónoma e independiente; es la mujer quien elige la microempresa que va a fundar y que luego administrará, asignando tareas a los demás integrantes de la familia.

Este cambio de roles en la conducción de la familia es también un cambio simbólico que la mujer percibe como una equiparación con la figura dominante del marido: adquiriendo confianza en sí misma, en sus capacidades, la mujer percibe que puede ser autónoma de la protección económica y social del marido y hasta puede decidir divorciarse, si el vinculo matrimonial representa solamente una protección económica. Los hombres no hablan al respecto y muchas veces subestiman el papel que las mujeres tuvieron en la experiencia del trueque; por el contrario, muchas mujeres subrayan el cambio que se 
produjo en su vida familiar y de pareja al participar en el trueque. Uno de los efectos más relevantes del trueque es propio: el empoderamiento del género femenino.

[El trueque] me permitió participar con la gente, me dio protección, tomé decisiones importantes como la de separarme de mi marido, porque me sentía contenida. Lo más importante es que despertó mi capacidad creativa, me animó a ser y, en segundo lugar, fue una ayuda económica. ${ }^{25}$

Contextualizando el fenómeno del trueque al interior de la tradición política, es fácil deducir que muchos de los principios en los cuales el trueque se basa son opuestos a las dinámicas y a las prácticas de la política argentina, en particular de la política que se relaciona con la clase media-baja y con la pobreza estructural. Contrariamente a las políticas asistencialistas y populistas del peronismo, también implementadas por otros partidos, el sistema del trueque se basa en una cultura del trabajo independiente de las instituciones estatales y de los partidos políticos. Los prosumidores dejan de «pedir» al Estado que les provea su supervivencia; dejan de someterse a las amenazas de los partidos políticos que ofrecen «pan a cambio de votos»: los prosumidores comienzan a ocuparse de su presente y su futuro reapropiándose de la capacidad colectiva de poder cambiar el statu quo, en particular, de poder trabajar y sustentarse de manera autónoma e independiente de las instituciones estatales.

Para entender la importancia de este cambio de mentalidad y de prácticas es necesario remarcar cómo el asistencialismo y el clientelismo peronista están radicados sobre todo en los barrios de clase media-baja y en las villas miseria de la pobreza estructural: el aparato peronista está constantemente presente en estos lugares a través de sus «punteros», que a su vez se apoyan en las «manzaneras», quienes están en contacto directo con la población a la cual distribuyen alimentos y de la cual obtienen votos; ${ }^{26}$ ya son tres las generaciones de argentinos que se encuentran bajo la línea de pobreza por ser amenazadas con esta forma subrepticia de asistencialismo que les da la posibilidad de sobrevivir negándoles la posibilidad de vivir, esto es, de trabajar.

Rechazar la limosna es el primer paso para salir de un círculo vicioso como el mencionado, y es esto lo que el trueque siempre propuso. 
Además, cuando el Estado y el peronismo no han logrado continuar sosteniendo tal asistencialismo, las manzaneras se convirtieron en «coordinadoras» de los Clubes de Trueque: continuaron manteniendo el papel de distribuidoras de víveres pero sin apoyarse en el peronismo, autonomizándose y autogestionándose.

El rechazo del dinero y del peso en los Clubes de Trueque más que un rechazo al capitalismo en general es un deseo de autonomía respecto a lo que la moneda de curso legal representa: el Estado. Aquel Estado gobernado como si fuera una res privata, que hipoteca el futuro de los argentinos, vende lagos y montañas, polariza la sociedad. El Estado y los partidos no son más un referente, y si bien no es posible afirmar que el trueque haya sido una experiencia satisfactoria de autoorganización, es posible afirmar, en cambio, que fue una gran experiencia lograda de autonomización de las instituciones formales: una experiencia que, a diferencia del Estado, fue capaz de realizar la utopía de una sociedad sin marginados.

La eficiencia del trueque en la distribución de los recursos resultó tal que fueron las instituciones quienes facilitaron el fenómeno del trueque promoviéndolo y declinándolo de interés municipal, sobre todo, en aquellos famosos ocho meses $^{27}$ de falta de subsidios al desempleo; no se puede obviar que en tal situación el trueque fue utilizado por las instituciones como válvula de escape por millones de personas, tornándose así funcional al sistema. La gran eficiencia del trueque menoscabó la red clientelar peronista y reunió en los Clubes más gente que cualquier partido hubiera podido convocar, en un momento de gran desconfianza hacia las instituciones. Estos efectos no previstos provocaron una especial atención por parte de los partidos políticos ya que temieron que el fenómeno del trueque y sus ideólogos, de haber accedido a la política, hubieran conseguido una gran cantidad de votos; al mismo tiempo el fenómeno fue instrumentalizado por los punteros que abrieron Clubes de Trueque para asegurarse un determinado séquito. Los ideólogos estaban seguros de que el poder político y económico había tenido un rol importante en el fenómeno de falsificación de créditos y en otros intentos de descrédito y sofocamiento del fenómeno.

Las instituciones y los poderes políticos y económicos notaron, más que los intelectuales y estudiosos, la verdadera fortaleza del trueque: ser un sistema capaz de 
devolver confianza a la acción colectiva en tanto capacidad de trasformación de la realidad por parte de una comunidad.

\section{CONCLUSIONES}

La importancia del trueque reside en haber sido la herramienta a través de la cual los pobres y marginados no solamente hicieron frente a sus necesidades materiales, sino que además pudieron reconstruir los lazos sociales indispensables para la vida en comunidad. El Club de Trueque fue un espacio en el cual las personas intentaron recuperar la confianza en sí mismas y donde construyeron un nuevo tipo de comunidad desvinculada de las características de la sociedad argentina capitalista: el individualismo y el asistencialismo. Incitadas por las necesidades económicas, las personas lograron superar el aislamiento de las relaciones impersonales capitalistas y redescubrieron la fuerza y el involucramiento de la acción común que les permitió tornarse protagonistas de su presente sin limitarse a «pedir» a instituciones lejanas e indiferentes el permiso y la oportunidad para sobrevivir. En los Clubes de Trueque se creó una nueva forma de sociabilidad por la cual no solamente las personas sobreviven sino «viven»: se sienten vivas porque son útiles para los otros; redescubren sus capacidades productivas y redescubren a «los otras» como recursos para un bienestar común o como destinatarios de gestos de solidaridad y reciprocidad.

La experiencia del trueque para muchas personas representó la posibilidad de sentirse integradas en «otra» sociedad, en la cual no estaban marginadas sino le presentaban el centro. Este sentido de protección y vitalidad, causado por la participación en un proyecto común, les permitió romper con determinadas estructuras típicas de la sociedad capitalista. Las consecuencias objetivas más relevantes del fenómeno del trueque más que estar relacionadas con lo económico se relacionan con la reestructuración de las relaciones familiares por el empoderamiento de las mujeres en el sistema del trueque; el parcial quiebre con la mentalidad asistencialista y con la organización de punteros y manzaneras ligados al sistema clientelar-asistencialista peronista, en particular, la autonomización de las instituciones a través de una acción colectiva basada en nuevas relaciones de confianza entre las personas. 
Al considerar el éxito social del fenómeno del trueque es posible comprender por qué en 2005 las personas signen yendo a los Clubes de Trueque, no obstante el escándalo de los créditos falsificados y el derrumbe del sistema. El hecho es que a diez años de su aparición continúa siendo un experimento social abierto a la creación de una nueva sociabilidad, y es en esto donde reside su valor sociológico. 


\section{BIBLIOGRAFÍA}

Almeyra, Guillermo, 2004, La protesta social en la Argentina (1990-2004). Ediciones Continente, Buenos Aires.

Covas, Horacio Rubén y Carlos Alberto de Sanzo, 1997, Clubes de Trueque. Ediciones de Programa de Autosuficiencia Regional, Bernal.

Di Tella, Torcuato, 1998, Historia social de la Argentina contemporánea. Troquel, Buenos Aires.

Gonzáles Bombal, Inés, Fabiana Leoni y Mariana Luzzi, 2002, «Nuevas redes sociales: los clubes de trueque», Seminario Internacional Respuestas de la Sociedad Civil a la Emergencia Social: Brasil y Argentina Comparten Experiencias, noviembre. Università di San Paolo, San Paolo.

Hintze, Susana (comp.), 2003, Trueque y Economía Solidaria, Prometeo Libros, Buenos Aires.

Latouche. Serge, 2000, L 'altra Africa (Tra dono e mercato). Bollati Boringhieri. Torino.

Marx, Karl, 1978 [1857-1858], Lineamenti fondamentali della critica dell'economia politica. La Nuova Italia, Firenze.

Merton, K. Robert. 1983 [1949], Teoria e Struttura Sociale. Il Mulino, Bologna.

Minujin, Alberto (comp.), 1992, Cuesto Abajo. Los nuevos pobres: efectos de la crisis en la sociedad argentina. UNICEF, Losada, Buenos Aires. 
Pereyras, Flora, 2004, «Los clubes de Trueque en la ciudad de Buenos Aires. Estrategias de supervivencia de las clases medias», II Congreso Nacional de Sociología. Buenos Aires.

Pittau, Maurizio, 2003, Economie senza Denaro (i sistemi di scambio non monetario nell'economia di mercato). EML, Bologna.

Powell. Jeff, 2002, «Petty Capitalism. Perfecting Capitalism or Post-Capitalism? Lesson IV on the argentinian barter network», Working paper, núm. 357. ORPAS, Institute of Social Studies.

Primavera, Heloisa, 2001, Cómo comenzar una red de trueque solidario. RedLASES, Buenos Aires.

Seoane, María, 2003, El Saqueo de la Argentina. Editorial Sudamericana, Buenos Aires.

Tommasi, Mariano, 2002. «Crisis, political institutions, and policy reform». Annual World Bank Conference on Development Economics, junio. Universidad de San Andrés \& Center of Studies for Institucional Development, Oslo, Europe.

Vieyra, Víctor Lucio, 2002, Trueque-Valor Humano Energético Manual instructivo. Editorial Víctor Lucio Vieyra, Buenos Aires.

Zibechi, Raúl, 2001, Genealogia della rivolta Argentina. La società in movimento. Luca Sassella editore, Roma. 


\section{Notas}

\footnotetext{
${ }^{1}$ El ensayo presenta reflexiones elaboradas a partir de una investigación desarrollada en dos fases diferentes: una investigación de campo durante cuatro meses - de septiembre de 2004 hasta enero de 2005- en el conurbano de Buenos Aires -observación participante, entrevistas con los fundadores del trueque, con prosumidores, con empresarios y gente común; recolección de documentales, diarios locales, participación directa en reuniones, eventos etc.-; y la sucesiva elaboración teórica. Por motivos de espacio y contexto, la parte empírica de la investigación tiene un espacio reducido, si bien representa el material a partir del cual se elaboraron las reflexiones presentadas.

${ }^{2}$ Por «financiarización de la economía» se entiende una configuración de las relaciones entre el sistema productivo y el sistema financiero, en la cual el ámbito financiero domina y determina el funcionamiento del ámbito productivo.

${ }^{3}$ María Seoane, economista y periodista argentina, titula su libro El saqueo de la Argentina para resumir el sentido y las consecuencias de treinta años de políticas neoliberales. Seoane, María, 2003, El saqueo de la Argentina. Editorial Sudamericana, Buenos Aires.

${ }^{4}$ Para analizar el tema de la historia de los movimientos argentinos hasta los años noventa: Zibechi, Raúl, 2003, Genealogia della rivolta. Argentina. La società in movimento. Luca Sassella editore, Roma.

${ }^{5}$ Para analizar el tema de las protestas sociales en los años noventa y en los primeros años del siglo XXI: Almeyra, Guillermo, 2004, La protesta social en la Argentina (1990-2004), Ediciones Continente, Buenos Aires.

${ }^{6}$ Aunque a lo largo del artículo será mencionada la categoría de «clase media» sin ulteriores matices, es preciso especificar que los fundadores del trueque pertenecían a un sector muy particular y pequeño de las «clases medias argentinas», es decir, al grupo de profesionales y/o intelectuales con perspectiva progresista, apartidaria y refractaria tanto a los efectos sociales y ambientales del capitalismo globalizado como del estado paternalista y clientelar. Al contrario, la mayoría de los sectores empobrecidos de la clase media, al enfrentar la crisis, se reveló muy conservadora y hasta discriminatoria hacia los sectores populares, en relación a los cuales quería seguir marcando la diferencia de estatus social.

${ }^{7}$ Horacio Covas, Carlos de Sanzo, Rubén Ravera.

${ }^{8}$ Por «antiguo trueque» se entiende una forma de intercambio de productos no monetaria y no regulada por un sistema de normas institucionalizado, típica de las sociedades no complejas.

${ }^{9}$ Para analizar el tema de los efectos de la crisis económica en la clase media argentina: Minujin, Alberto (comp.), 1992, Cuesta Abajo. Los nuevos pobres: efectos de la crisis en la sociedad argentina. Unicef, Losada, Buenos Aires.

${ }^{10}$ A lo largo del ensayo, con el término comunidad se entiende un grupo restringido de personas que entran en relaciones directas al compartir un mismo espacio de acción.

${ }^{11}$ Para profundizar la relación entre «mercaderías», «valor de cambio» y «dinero»: Marx, Karl, 1978 [18571858], Lineamenti fondamentali della critica dell'Economica Politica. La Nuova Italia, Firenze.

${ }^{12}$ Merton, K. Robert, 1983 [1949], Teoria e Struttura Sociale. Il Mulino, Bologna.

${ }^{13}$ Entrevista prosumidor núm. 10, 30/10/2004.

${ }^{14}$ Entrevista prosumidor núm. 6, 30/10/2004.

${ }^{15}$ Entrevista prosumidor núm. 11, 30/10/2004.

${ }^{16}$ Entrevista prosumidor núm. 15, 30/10/2004.

${ }^{17}$ Entrevista prosumidor núm. 21, 31/10/2004.

${ }^{18}$ Entrevista prosumidor núm. 30/10/2004.

${ }^{19}$ Entrevista prosumidor núm. 2, 27/10/2004.

${ }^{20}$ Entrevista prosumidor núm. 3, 27/10/2004.

${ }^{21}$ Entrevista prosumidor núm. 20, 30/10/2004.

${ }^{22}$ Entrevista prosumidor núm. 19, 30/10/2004.

${ }^{23}$ Entrevista prosumidor núm. 20, 30/10/2004.

${ }^{24}$ Entrevista prosumidor núm. 2, 27/10/2004.

${ }^{25}$ Entrevista núm. 5, coordinadora Susana Rivano, 3/11/2004.
} 
${ }^{26}$ Es preciso especificar que en los años 90 las políticas sociales impulsadas por el peronismo se «territorializan», es decir, no tienen más como beneficiarios específicos capas de la población relacionadas con su posición en el sistema laboral —obreros, empleados_-, sino que son orientadas a dar asistencia a determinados territorios urbanos en los cuales se concentra la población más vulnerable. Estas políticas sociales territorializadas son una respuesta al evidente repliegue hacia el barrio de las clases populares afectadas por altísimos índices de desocupación —aproximadamente de 20\%—; la imposibilidad de realizar sus inscripción social a través del trabajo, obliga a las clases populares a utilizar el «barrio» como único medio a través del cual buscan estrategias de supervivencia $\mathrm{y}$, de alguna manera, una mínima integración social. Al fin de implementar políticas asistenciales en cada barrio carente, el gobernador peronista de la Provincia de Buenos Aires (Duhalde) fortalece la presencia territorial del partido agregando al grupo de «punteros», es decir de cuadros bajos del partido encargados de llevar adelante las relaciones con la clases populares, un grupo de «manzaneras»: mujeres encargadas de la distribución, en cada manzana, de los beneficios otorgados a los más pobres — principalmente, comida- En los años 90, entonces, las políticas sociales se tornan aún más asistenciales y apuntan a paliar las urgencias de específicos territorios sin proponerse un real cambio de la situación de aguda marginalización en la cual se encuentran las clases populares. Este sistema de asistencialismo, aumentando la dependencia de los pobres del aparato territorial del partido peronista, causa un progresivo desarrollo de las dinámicas clientelares gestionadas por las manzaneras y los punteros.

${ }^{27}$ De octubre de 2001 hasta mayo de 2002.

Fecha de recepción: 5 de febrero de 2008 .

Fecha de aceptación: 2 de julio de 2008. 